Book Review:

Judul Buku : Zaini Dablan Sang Guru

Penulis : Edy Suandi Hamid, dkk

Penerbit : UII Press, Yogyakarta

Cetakan : Pertama, 2009

Tebal : 184 halaman + indeks

\title{
DINAMIKA KESEDERHANAAN DAN KETELADANAN SANG GURU
}

\author{
Oleh: Husain Haikal*
}

Dinamika hidup Zaini Dahlan selalu dilandasi wahyu dan dimantapkan ilmu seirama dengan ayat-ayat qauliyah yang ditekuninya. Wajarlah apabila dinamika hidupnya indah, cukup berwarna walau tetap sederhana hingga dapat menjadi teladan setiap insan. Semua ini tidak lepas dari kisi-kisi ayat-ayat kauniyah yang berlandaskan ayat-ayat qauliah yang bermutu karena dimantapkan ilmu.

Dinamika hidupnya penuh beragam ujian. Betapa tidak, seturut penuturan menantunya, Abdul Nasir, Zaini bertahan hidup hanya dengan satu paru-paru setelah menjalani operasi paru-paru ketika belajar di Kairo. ${ }^{1}$ Walau demikian, Zaini selalu ringan tangan dalam artian senang membantu. Abdul Nasir sendiri bersama Abdul Haq, keduanya berasal dari Korea, pernah tinggal di garasi rumah dinas Zaini selama 8 bulan dan diberi makan secukupnya tanpa dipungut biaya sepeser pun saat menempuh studi S3 IAIN Sunan Kalijaga. Pada saat itu Zaini menjabat rektor IAIN Sunan Kalijaga.

* Husain Haikal adalah dosen UNY, sempat menjadi dosen tamu di UKM (Universiti Kebangsaan Malaysia) 1991-1993, dan USM (Universiti Sains Malaysia) 1993-1996. Email: h_haikal2005@yahoo.com

1 Abdul Nasir, "Sosok Mertua Penolong Yang Tulus", dalam Edy Suandi Hamid dkk., Zaini Dablan Sang Guru, (Yogyakarta: UII Press, 2009), hal. 169. 
Hidup Zaini jauh dari gelimang harta. Dia sangat sederhana. Istrinya pernah menuturkan bahwa di tahun 1965 saat memulai hidup di Cirebon hanya dengan harta yang cukup dimuat satu becak ditambah dengan dua orang tua dan dua orang anak. ${ }^{2}$ Figur Zaini dikenal santun dan anggun serta kaya anugerah Allah dalam beragam bidang. Dilahirkan di Temanggung pada 25 Desember 1926. Tokoh ini kaya dalam beragam pengalaman dan terbiasa hijrah ke berbagai tempat karena belajar atau bekerja.

Selain itu, Zaini telah tampil sebagai salah satu cendekiawan yang mumpuni dengan karya monumentalnya, Qur'an Karim dan Terjemahan Artinya. ${ }^{3}$ Dalam penulisan karya ini Zaini banyak dibantu para sahabat yang sangat menginginkan agar upaya itu segera terwujud. ${ }^{4}$

\section{Tentang Pendidikan, Karier dan Keluarga}

Selesai studi di PTAIN Yogyakarta tingkat Sarjana Muda, Zaini mendapat beasiswa kuliah sastra Arab di Cairo University. Selesai studi Zaini menikah dengan Siti Lathifah dari Kendal pada 1961 dan dianugerahi 4 orang anak. Semua anugerah diperoleh Zaini setelah lulus aneka ujian, salah satunya pada 14 Pebruari 1964 dipenjara selama 3,5 bulan pada zaman pemerintahan Bung Karno karena didakwa menggagalkan pesta olahraga Ganefo.

Sebelum dipenjara semasa pemerintahan Bung Karno, Zaini bertugas di IAIN Sunan Kalijaga dan berperan dalam pembukaan Jurusan Sastra Arab di Fakultas Sasdaya, Sastra dan Budaya, (sekarang Fakultas Ilmu Budaya) UGM. Selepas dipenjara, Zaini menjadi dosen di IAIN Jakarta. Kemudian pada 1965 ditugaskan di IAIN Cirebon menjadi Sekretaris Fakultas Tarbiyah, dan berlanjut menjadi Dekan Fakultas Ushuluddin selama 6 tahun. Pada 1971 Zaini menjadi anggota DPRD Cirebon.

2 Siti Lathifah, "Indahnya Mengarungi Samudera Kehidupan Bersama Pak Zaini”, dalam Edy Suandi Hamid dkk., Zaini Dablan Sang Guru..., hal. 150.

3 Terjemahan ini harus dilakukan karena setiap tahun saat menerima mahasiswa baru, sulit bagi UII untuk mendapatkan Al-Qur'an dan Terjemahnya terbitan Depag dalam jumlah yang memadai. Dalam pengantar buku Zaini menegaskan bahwa terjemahan ini berusaha untuk mendekatkan pengertian ayat kepada para pembaca, sehingga kadang-kadang perlu melepaskan terjemahan harfiah dan mengutamakan pengertian dalam kemasan bahasa Indonesia yang mudah dicerna. Zaini Dahlan, "Prakata", dalam Zaini Dahlan dan Azharudin Zahil, Qur'an Karim dan Terjemahan Artinya, (Yogyakarta: UII Press, 2000), hal. ix.

4 Mereka itu seperti Azharudin Zahil, Aunur Rahim Faqih, Muhadi Zainuddin, M. Tamyiz, A. F. Djunaidi Syafe'i, Muzhoffar Akhwan, Muhammad Hasyim, Amir Mu’allim, Barmawi Mukri, Barmawi Munthe, Yazid Nasrullah, Akhmad Muhadi, M.B. Muhlison, dan Hastuti Saptorini. Ibid., hal. x. 
Hanya saja, setelah Fakultas Ushuluddin di IAIN Cirebon ditutup, pada 1973 Zaini ditugaskan menjadi Kakanwil Depag Jawa Barat dan berkantor di Bandung.

Sekitar tiga tahun kemudian Zaini ditugaskan menjadi Rektor IAIN Sunan Kalijaga selama dua periode (1976-1984). Usai sebagai rektor, Zaini segera ditugaskan sebagai Dirjen Binbaga Islam Depag, membawahi 4 direktorat, yaitu Direktorat Pendidikan Agama pada Sekolah Umum, Direktorat Pendidikan Agama, Direktorat Pendidikan Tinggi Agama, dan Direktorat Peradilan Agama. Selanjutnya Zaini berkiprah di UII, sebagai Ketua Presidium, Wakil Ketua Badan Wakaf, dan Ketua Badan Wakaf (1993-6). Jabatan ketua ini terpaksa dilepaskan karena Zaini harus memegang amanah sebagai rektor UII (1994-2002). Sekarang tokoh ini tetap giat berdakwah dan menulis serta aktif dalam berbagai organisasi sosial kemasyarakatan. ${ }^{5}$

Semua pencapaian ini dapat dikatakan erat berkaitan dengan latar belakang keluarga $^{6}$ dan pendidikan Zaini. Sayang dalam buku ini belum ditampilkan secara bermakna latar belakang keluarga Zaini Dahlan, apalagi uraian mengenai keluarganya relatif sedikit bila dibandingkan sajian mengenai pendidikan yang telah ditempuhnya. Benar telah ada sedikit uraian dari keluarga tetapi para pembaca akan bertanya-tanya siapakah ibu dan ayahnya serta bagaimana dengan pendidikan dan pekerjaan ayahnya.

Serba kekhasan buku ini yang sedikit mengungkap keluarga Zaini, mengundang para pembaca, lebih-lebih lagi para mahasiswa, apalagi mahasiswa UII, dan keluarganya, untuk segera menulis serta menyajikan biografi Zaini secara utuh dan menyeluruh. Lepas dari kekhasan buku ini, Zaini sebagai pengkaji sastra, sangat cinta kepada Negara Kesatuan Republik Indonesia. Zaini telah terketuk untuk menuliskan berbagai puisi, salah satunya adalah keprihatinan tentang dinamika perjuangan Aceh: Mari kita bangkit bersama, bergandeng tangan dan hati menegakean cita-cita bangsa//Merajut kembali benang-benang yang telab terjulur panjang//Menata bata-bata yang pecab berantakan//Dengan tangan kita sendiri yang baru//Dengan semangat kita sendiri yang segar//Dan dengan akidah kita yang kuat dan mantap//Masih relakah kami ditinggal sendirian?

\footnotetext{
5 "Biografi Singkat Prof. Zaini Dahlan”, dalam Edy Suandi Hamid dkk., Zaini Dablan Sang Guru..., hal. 179-180.

6 Pentingnya keluarga terutama ibu dan bapa banyak disajikan dalam aneka karya, salah satunya dapat dikaji dari Muhammad al Fahham, "Sa'adah al-Abna fî Bir al-Ummahât wal al-Aba", diterjemahkan Ahmad Hotib, Berbakti kepada Orang Tua Kunci Kesuksesan, (Bandung: Irsyad Baitussalam, 2006).
} 
Beberapa larik puisi di atas sangat mengesankan bagi para pendengar, sehingga ada yang masih ingat dan disajikan lagi saat menulis dinamika kehidupan Zaini. ${ }^{7}$ Apa yang telah disajikan dalam buku ini cukup bermakna bagi dinamika hidup berbangsa, khususnya bagi umat Islam.

Sajian buku benar-benar bermakna karena mengetengahkan dinamika seorang cendekiawan yang tampil sebagai salah satu contoh pendidik dan pemimpin teladan. Setelah sambutan Rektor UII, "Pengantar Editor" buku ini dipilah dalam empat bab. Bab I Kepemimpinan dan Keteladanan di Arena Publik (1-56) yang berisi tulisan berbagai tokoh dan figur-figur pemimpin UII dan mereka yang mengenal Zaini. Dilanjutkan dengan Bab II Kesantunan dan Keikhlasan Bersama Kolega (57-109) merupakan sajian teman-teman Zaini seperti teman sekolah, dosen, dan karyawan. Sedangkan Bab III Kharismatik dan Bijaksana Mengelola Karyawan (111-145) yang menyajikan kesan dan pesan para karyawan yang relatif akrab dengan Zaini. Bab terakhir buku ini, yaitu Bab IV Kehangatan dan Berkah di Tengah Keluarga (147180), mengetengahkan sajian dari keluarga yang diwakili istri, anak, dan menantu serta salah seorang kerabat dekat Zaini.

\section{Figur Pemimpin Teladan}

Proses pendidikan Zaini dimulai dari pondok pesantren. Sore hari ia masih harus bersusah payah belajar di Madrasah Aliyah. Kenyataan ini dituturkan dengan jujur oleh Bahri bin Abu Bakar: saya dan Mas Zaini tinggal bersama di Pesantren Kiai Ali yang terletak di sebelah selatan masjid Parakan. Berbeda dengan saya yang hanya "ngaji" di pesantren, Mas Zaini juga sekolah di Madrasah Aliyah Al-Iman, utara masjid Parakan. ${ }^{8}$

Proses pendidikan pondok pesantren sampai saat ini belum begitu diapresiasi oleh pemerintah. Elite bangsa ini, termasuk para cerdik cendekiawan, masih memicingkan mata terhadap dinamika proses belajar dan mengajar di pondok pesantren. Bisa jadi semua ini adalah warisan paradigma pemikiran penjajah Belanda. Padahal umumnya dari pondoklah lahir para pejuang kemerdekaan yang ampuh

7 Moh. Mahfud MD, "77 Tahun Prof. Zaini Dahlan M.A”, dalam Supardi dan Herien Priyono Eds., Gaya Santri Kedu Mengelola Korporasi, Diri dan Keluarganya. Tulisan Mahfud MD ini diolah kembali menjadi "Pak Zaini dengan Wajah Teduh dan Sikap Teguh" dalam Edy Suandi Hamid dkk., Zaini Dablan Sang Guru..., hal. 21.

8 Bahri bin Abubakar, "Jujur, Baik, dan Polos", dalam Edy Suandi Hamid dkk., Zaini Dablan Sang Guru..., hal. 89. 
dan tangguh yang tak kalah dengan para lulusan sekolah serta alumni bangku kuliah. Berkaitan dengan serba kelemahan pondok, cukup bermakna sajian alumnus pondok yang sempat tampil sebagai menteri agama. Antara lain dia menuliskan:

"Bagaimana kekurangan-kekurangan itu tidak dialami oleh Pesantren [sic.] padahal pesantren adalah hasil jerih payah dari mujahadah para 'Ulama turun temurun dari kakek atau ayah atau guru, suatu proyek swasembada dari Rakyat [sic.] yang berdikari, padahal Rakyat [sic.] adalah begitu miskin hidupnya lantaran penjajahan dan keterbela-kangan yang memerlukan pimpinan yang ramah dan penuh Kasih [sic.] sayang secara terus menerus tanpa mengenal rasa bosan atau 9

Biasanya semua pihak yang berkuasa, termasuk mereka yang sama menggumuli bidang pendidikan, saling tunjuk hidung atas berbagai ketimpangan yang ada. Ini berbeda dengan sikap Zaini. Bayangkan aneka beban yang disyaratkan bagi guru calon penerima dana tunjangan profesi harus lulus sertifikasi baik melalui program portofolio atau Pendidikan dan Latihan Profesi Guru (PLPG), bagi yang gagal ikut sertifikasi lewat portofolio. Sedangkan bagi para calon guru disyaratkan harus lulus S1 agar dapat melahirkan pendidikan bermutu. Sementara bakal calon anggota legislatif dan eksekutif tingkat daerah maupun pusat bahkan juga seorang bakal calon presiden cukup berijazah sekolah lanjutan atas. Mudah dipahami apabila nantinya lahir para penguasa bukan pemimpin. Semua ini terjadi karena lemahnya pendidikan di Indonesia, sehingga ada yang tanpa ragu-ragu menuliskan:

“...hingga saat ini tidak ada orang yang tahu persis gambaran utuh keadaan pendidikan nasional Indonesia. Dalam rangka otonomi daerah, sebaiknya Bappeda mengkoordinasikan inventarisasi data menyeluruh tentang pendidikan di tingkat daerah. Hasil inventarisasi itu dianalisis lebih lanjut untuk mengetahui kekuatan dan kelemahan sistem yang ada guna ditindaklanjuti". ${ }^{10}$

Wajarlah apabila para pemimpin menjadi langka, sulit didapatkan pada saat sekarang ini. Beruntunglah masih ada contoh nyata seorang pemimpin yang berwibawa walau telah berusia senja. Zaini adalah salah satu contoh utamanya. Apakah pendidikan pondok, pendidikan UII, atau pendidikan Mesir amat mewarnai pendidikan Zaini? Atau ketiga-tiganya saling memengaruhi secara seimbang.

9 Saifuddin Zuhri, Sejarah Kebangkitan Islam dan Perkembangannya di Indonesia, (Bandung: Al-Maarif, 1981), hal. 605.

10 Fasli Jalal dan Dedi Supriadi (Ed), Reformasi Pendidikan dalam Konteks Otonomi Daerah, (Yogyakarta: Adicita, 2001), hal. lii. 
Pendidikan perlu ditekankan karena Indonesia yang lama mengabaikan pendidikan tertingggal dibanding negara jiran, baik Brunei, Malaya, dan Singapura yang mengutamakan pendidikan.

Dalam kaitan ini patut direnungikan kalimat berikut: The destiny of India now is being shaped in her classrooms. This, we believe, is no mere [sic.] rethoric ... it is education that determines the level of prosperity, welfare and security of the people. ${ }^{11}$ Bagaimana sajian ini dapat dilaksanakan secara bermakna dengan melihat aneka kekhasan Indonesia, serta bukan sekadar wacana. Bila dapat diamalkan, seperti juga dalam keamanan dan kesehatan, agar pendidikan menjadi perhatian utama, secara bertahap citra Indonesia akan meningkat.

Apa beda pemimpin dan penguasa? Pemimpin lahir dari 'didikan' zaman dan lebih mementingkan kewajiban dan tidak peduli dengan haknya sendiri. Memang jalan pemimpin bukan jalan yang mudah. Memimpin adalah jalan menderita. Ini sejalan dengan ucapan Kasman: Een leidersweg is een lejdensweg. Leiden is Leyden. Khas ucapan dan tindakan para pemimpin kemerdekaan terbukti selain dipenjara oleh penjajah, juga dipenjara penguasa setelah Indonesia merdeka. ${ }^{12}$ Mereka yang dipenjara karena dianggap 'pengkhianat', seperti Kasman, Moh. Natsir, Roem dan Sjahrir ${ }^{13}$ hanya karena mereka berani mengingatkan penguasa masa Orde Lama. Zaman Orde Baru tak banyak berbeda sebab tak sedikit aktivis yang dibunuh.

Harus diakui, figur Zaini mulai karir dari anak tangga yang terbawah. Beberapa teman atau koleganya mempunyai beragam penilaian yang cukup khas tentangnya. Wajarlah ada yang mengatakan sajian dalam buku ini sekadar mujamalah sejalan dengan beragam tulisan yang ada. Benar-benar menyentuh gaya bicara dan nasihat Zaini yang benar-benar tidak menggurui tetapi sejuk serta

11 Ronald Dore, “The Diploma Disease”, dalam M. Oepen \& W. Karcher (eds.), The Impact of Pesantren, hal. 156.

12 Lihat Moh. Roem, "Haji Agus Salim Memimpin adalah Menderita", dalam Yanto Bashri dan Retno Suffatni (eds.), Sejarah Tokoh Bangsa, (Yogyakarta: LKIS, 2004), hal. 122-123.

13 Nasib tragis dialami Sjahrir yang pernah tiga kali menjadi menjadi perdana menteri pada awal kemerdekaan. Saat dipenjara dia sakit dan tidak diizinkan berobat. Baru setelah makin parah dan tidak mampu berbicara lagi, mendapat izin berobat. Sayangnya sudah terlambat dan akhirnya wafat. Saat dikebumikan, status Sjahrir berubah menjadi pahlawan bukan lagi pengkhianat atau penjahat. "Ditahan sebagai pengkhianat negara selama kurang lebih tiga tahun, dibebaskan, diberi kesempatan berobat ke Swiss, dan pada hari meninggalnya 19 April 1966 langsung diakui sebagai pahlawan nasional" Y. B. Mangunwijaya, "Sutan Sjahrir Antara Pemikir dan Politikus, dalam Yanto Bashri dan Retno Suffatni (eds.), Sejarah Tokoh Bangsa..., hal. 71. 
puitis dan disajikan tidak menggebu-gebu tetapi dengan sunggingan senyum menawan. Para pendengarnya, termasuk Ahmad Syafii Maarif cukup terpana. Sampai-sampai Syafii mengatakan:

Hati nurani yang bersih, wahyu Al-Qur'an, air sumur yang tak berasa dan tak berbau, siapa yang menganggapnya sebagai karunia? Semua perhatian terkunci mati bahwa hanya: harta, harta, harta. Rumah gedung, mobil mewah, jabatan itulah yang harus diburu dengan cara apa pun. Harus aman sampai anak cucu. Hanya harta yang dianggap bisa menolong manusia. Tuhan, cukup disebut dalam doa saja. Tuhan hanya dalam doa, tapi dalam action hartalah Tuhan sejati. ${ }^{14}$

Sebaliknya, seorang penguasa akan mengutamakan hak dan berusaha keras untuk mendapatkan hak kalau perlu secara batil. Bagi penguasa semua dinilai secara materi dalam bahasa mudahnya UUD, ujung-ujungnya duwit. Uang atau materi yang menentukan segalanya. Seturut ungkapan Idris Shah, sang penguasa hampir selalu menganggap dia sendiri atau peraturannya yang benar, sehingga dia memiliki sedikit kesempatan untuk memperhatikan perilakunya. ${ }^{15}$ Wajarlah apabila mereka tampil sebagai penguasa tunggal, diktator dan sejenisnya.

Tampilnya Zaini Dahlan diuntungkan dengan norma dan budaya yang wujud dalam masyarakat Indonesia yang terasa sekali aroma Islamnya. Apalagi figur ini diuntungkan dengan berbagai contoh nyata ${ }^{16}$ baik lokal atau nasional termasuk juga contoh-contoh dari dalam UII maupun dari luar. Ini antara lain terekam dalam sikap dan kerja A. Kahar Muzakkir dan Moh. Natsir. ${ }^{17}$

Budaya Islam dan Indonesia yang menghormati serta meneladani guru ini tampak berbeda sekali dengan serba norma dan budaya Barat klasik, yang dianggap sebagai landasan utama norma dan budaya Barat moderen. Hal ini antara lain tercermin dalam sajian Seneka seorang yang dikenal sebagai cendekiawan Yunani. Dalam Epistolae ad Lucilium antara lain dia mengatakan: "Kalau para dewa bukan main bencinya pada seseorang mereka dorong dia menjadi guru". ${ }^{18}$

14 Ahmad Syafii Maarif, "Perpaduan Kekuatan Zikir dan Fikir", dalam Edy Suandi Hamid dkk eds., Zaini Dablan Sang Guru..., hal. 1.

15 Idris Shah, "Thinkers of the East", terj. Ribut Wahyudi, Sang Guru Zaman Kisab-kisab dari Timur, (Yogyakarta: LKiS, 1999), hal. 175-176.

16 Lihat Khalid Muhammad Khalid, "Baina Yaday Umar", terj. A. Chairon Marzuki Di Hadapan Umar, (Yogyakarta: Mitra Pustaka, 2009), hal. 323.

17 Yusril Ihza Mahendra, "Mohammad Natsir: Modernisme Islam dan Demokrasi", dalam Yanto Bashri dan Retno Suffatni (eds.), Sejarab Tokob Bangsa..., hal. 271-298.

18 Omi Intan Naomi (ed.), Menggugat Pendidikan, Fundamentalis, Konservatif, Liberal, Anarkis, (Yogyakarta: Pustaka Pelajar, 1999), hal. viii. 
Jelaslah guru bukan profesi yang didambakan bahkan juga dibenci. Hal sejenis ini juga pernah menimpa Indonesia sejak merdeka karena serba terbatasnya penghasilan dan kesejahteraan guru, sementara tugas yang diemban makin bertambah. Menariknya mereka diharuskan kuliah lagi walau umumnya mereka, kecuali yang punya jabatan struktural, banyak yang mencari kerja sampingan untuk dapat menambah penghasilan.

Dalam salah satu kajian terbukti 31,7 \% kepala sekolah dasar, SD, 32,2\% guru SD, 33,1 \% kepala sekolah menengah pertama, SMP, 37,5\% guru Bahasa Indonesia sekolah lanjutan tingkat pertama, SLTP, $42 \%$ guru matematika SLTP mempunyai aneka pekerjaan sampingan. Pekerjaan tadi antara lain mengajar di sekolah lain, memberi les privat, kursus tambahan, dan memasarkan buku2 pelajaran serta alatalat tulis dan sejenisnya untuk sekedar dapat uang tambahan. ${ }^{19}$

Lebih memprihatinkan lagi keadaan guru-guru honorer, lebih-lebih lagi guru honorer swasta. Sebagian mereka ada yang jadi petugas parkir, tukang ojek, pekerja cleaning service, bahkan ada pula yang jadi pemulung. Memang ada pula para guru yang tetap bertahan dan tetap menekuni kegiatan sebagai guru dengan mengedepankan berkah. Budaya demikian tentunya makin langka karena makin besar tuntutan materi masyarakat.

Makin mantapnya kapitalisme berarti makin mantap pula kesenjangan antar yang kaya dan yang miskin. Antar gaji dan penghasilan mereka yang sekedar paspasan atau yang kurang dengan mereka yang bermandi uang sudah bukan lagi menjadi rahasia umum. Mereka yang bekerja di tempat kering seperti Pegawai Negeri Sipil, dengan mereka yang di Badan Usaha Milik Negara. Pernah suatu saat besarnya gaji seorang profesor kalah dibandingkan dengan gaji seorang satpam BUMN.

Sejak Orde Baru terjadi proses pemantapan kapitalisme, dan pendidikan jadi ladang bisnis, ${ }^{20}$ akhirnya bangsa ini memakai cara berpikir Barat. Mereka asyik dengan masalah jender, Badan Hukum Pendidikan serta sejenisnya. Bangsa kita makin tergantung dengan International Monetery Fund (IMF), sementara pendidikan makin terabaikan, sehingga membawa kejatuhan Orba.

19 Fasli Jalal dan Dedi Supriadi (ed), Reformasi Pendidikan..., hal. 241.

20 Dikenal pula beragam modelnya, seperti program S1 dan S2 pada Sabtu-Ahad yang berlimpah para peminatnya karena umumnya mereka sudah bekerja dan punya uang melimpah sebagai pegawai swasta atau BUMN. Lihat G.A. Guritno, "Sarjana Akhir Pekan", Gatra, 20 Desember 2003, hal. 21. Bahkan beberapa PTN, perguruan tinggi negeri, dan PTS mengenalkan program S3 dengan riset saja langsung menulis disertasi dan tanpa mengikuti satu macam kuliah apapun bentuknya. Tentunya dengan biaya yang cukup mahal. 
Seorang pemimpin teladan, apalagi seorang guru, selalu rela berkorban demi masa depan. Masa depan yang tidak jelas dan penuh tanda tanya tapi menantang karena penuh resiko. Semua ini perlu dihayati agar hidup lebih berarti. Nilai-nilai luhur ini dihayati dan diamalkan para pendiri UII. Cukup beruntung karena penulis sempat bertemu dan berdialog dengan sebagian para pendiri dan penggiat UII pada masa yang relatif awal dan penuh banyak tantangan. Baik figur-figur seperti Moh. Natsir, Abdul Kahar Muzakkir, dan Saifullah Mahyudin adalah tokoh-tokoh yang sepi ing pamrih, rame ing gawe. Mereka semua adalah figur teladan, seperti Zaini Dahlan, yang ikhlas mengamalkan kredo memberi serasa menerima, kehilangan serasa mendapat. Jelaslah para founding fathers UII ini cukup identik dengan para founding fathers RI karena mereka adalah guru, walau tidak sepanjang hayatnya.

Sebagai salah seorang alumnus pondok, Zaini Dahlan mengenalkan sistem pondok, katakanlah identik dengan program MAPK, Madrasah Aliyah Program Khusus. Hanya MAPK untuk tingkat SLA, sedang pondok pesantren UII untuk tahap awalnya khas untuk tingkat universitas, tapi hanya seorang mahasiswa untuk setiap propinsi, semuanya berjumlah 27. Hanya saja tidak setiap propinsi mengirimkan. Untuk angkatan pertama ada 27 santri tetapi dari 18 propinsi, dengan rincian 13 mahasiswa di Fakultas Tarbiyah, 12 mahasiswa Fakultas Syariah, dan 2 mahasiswa Fakultas MIPA. Mereka semua dapat pelayanan istimewa karena segala gratis termasuk biaya perjalanan dari propinsi hingga Yogya, bebas kuliah, dan disediakan pondokan lengkap dengan makanan serta sepeda untuk setiap mahasiswa. ${ }^{21}$ Hanya saja dari 27 orang tadi, hanya 22 yang selesai, 2 orang mendapat beasiswa ke Mesir, 3 orang lagi drop out, karena IPK tidak memenuhi syarat.

Figur Zaini yang disorot buku ini layak dijadikan tokoh teladan yang merasakan aneka zaman, baik zaman penjajahan yang penderitaan dan juga zaman kemerdekaan. Pelbagai terobosan positif yang dilakukan Zaini selama memimpin UII perlu diapresiasi. Edy Suandi Hamid dengan tulus menyatakan bahwa di masa Zaini UII berani keluar dari persoalan internal untuk kemudian membawa diri menjadi universitas yang siap bersaing menghadapi tantangan pendidikan baik nasional maupun internasional. ${ }^{22}$

21 Suyanto, "Bijak, Teduh, dan Ngayomi", dalam Edy Suandi Hamid dkk., Zaini Dablan Sang Guru..., hal. 132

22 Edy Suandi Hamid, "Sosok Yang Berkarya Tanpa Akhir", dalam Edy Suandi Hamid dkk., Zaini Dablan Sang Guru..., hal. 43. 
Semua ini berhasil dicapai karena sikap santun dan anggun Zaini yang bertangan dingin dan tampil dengan serba keteladanan lebih-lebih bila berkait dengan ajaran Al-Qur'an. Syafrudin Alwi sempat menyaksikan kemarahan Zaini kepada sebagian dosen dan karyawan, sebab mereka tidak setuju dengan ide penarikan zakat bagi para dosen dan karyawan yang dipotong langsung dari gaji. Bahkan, bagi mereka yang tidak setuju dengan ide penarikan zakat dipersilakan Zaini keluar dari UII. ${ }^{23}$

Buku ini lebih berhasil bila mau melengkapi dengan glossary. Walau demikian buku ini sanggup menampilkan Zaini sebagai sosok guru bermutu. Ini dibuktikan dengan dinamika kehidupannya sejak siswa hingga purna tugas yang tetap berkarya. Tampaknya figur ini mampu tampil dalam mengemban tugas baik sebagai birokrat maupun saat mengemban amanah saat sebagai dosen yang mampu mewujudkan ta'lim, tarbiyah, bahkan juga ta'dib.

\section{DAFTAR PUSTAKA}

Al-Fahham, Muhammad. 2006. "Sa'adah al-Abna fî Bir al-Ummahât wal al-Aba", diterjemahkan Ahmad Hotib, Berbakti kepada Orang Tua Kunci Kesuksesan. Bandung: Irsyad Baitussalam.

Alwi, Syafaruddin. 2009. "Pribadi yang Demokratik dan Menyejukkan", dalam Edy Suandi Hamid dkk. Zaini Dablan Sang Guru. Yogyakarta: UII Press.

Bakar, Bahri bin Abu. 2009. "Jujur, Baik, dan Polos", dalam Edy Suandi Hamid dkk. Zaini Dahlan Sang Guru. Yogyakarta: UII Press.

Guritno, G.A. 2003. "Sarjana Akhir Pekan”. Gatra. 20 Desember.

Hamid, Edy Suandi. 2009. "Sosok Yang Berkarya Tanpa Akhir”, dalam Edy Suandi Hamid dkk. Zaini Dablan Sang Guru. Yogyakarta: UII Press.

Khalid, Khalid Muhammad. 2009. "Baina Yaday Umar”, terj. A. Chairon Marzuki. Di Hadapan Umar. Yogyakarta: Mitra Pustaka.

Lathifah, Siti. 2009. "Indahnya Mengarungi Samudera Kehidupan Bersama Pak Zaini”, dalam Edy Suandi Hamid dkk. Zaini Dablan Sang Guru. Yogyakarta: UII Press.

23 Syafaruddin Alwi, "Pribadi yang Demokratik dan Menyejukkan", dalam Edy Suandi Hamid dkk eds., Zaini Dablan Sang Guru..., hal. 47. 
Maarif, Ahmad Syafii. 2009. "Perpaduan Kekuatan Zikir dan Fikir", dalam Edy Suandi Hamid dkk. Zaini Dablan Sang Guru. Yogyakarta: UII Press.

Mahendra, Yusril Ihza. 2004. "Mohammad Natsir: Modernisme Islam dan Demokrasi", dalam Yanto Bashri dan Retno Suffatni (eds.), Sejarab Tokoh Bangsa. Yogykarta: LKiS.

MD, Mahfud. 2009. "Pak Zaini dengan Wajah Teduh dan Sikap Teguh" dalam Edy Suandi Hamid dkk. Zaini Dablan Sang Guru. Yogyakarta: UII Press.

Naomi, Omi Intan (Ed.) 1999. Menggugat Pendidikan, Fundamentalis, Konservatif, Liberal, Anarkis. Yogyakarta: Pustaka Pelajar.

Nasir, Abdul. 2009. "Sosok Mertua Penolong Yang Tulus”, dalam Edy Suandi Hamid dkk eds. Zaini Dablan Sang Guru. Yogyakarta: UII Press.

Roem, Moh. 2004. "Haji Agus Salim Memimpin adalah Menderita", dalam Yanto Bashri dan Retno Suffatni (eds.), Sejarah Tokoh Bangsa. Yogyakarta: LKiS.

Shah, Idris. 1999. "Thinkers of the East”, terj. Ribut Wahyudi, Sang Guru Zaman Kisah-kisah dari Timur. Yogyakarta: LKiS.

Supriadi, Fasli Jalal dan Dedi (Ed). 2001. Reformasi Pendidikan dalam Konteks Otonomi Daerah. Yogyakarta: Adicita.

Suyanto. 2009. "Bijak, Teduh, dan Ngayomi”, dalam Edy Suandi Hamid dkk. Zaini Dablan Sang Guru. Yogyakarta: UII Press.

Zahil, Zaini Dahlan dan Azharudin. 2000. Qur'an Karim dan Terjemahan Artinya. Yogyakarta: UII Press.

Zuhri, Saifuddin. 1981. Sejarah Kebangkitan Islam dan Perkembangannya di Indonesia. Bandung: Al-Maarif. 